\title{
Design aspects of operation of water supply facilities of pumping stations
}

\author{
Naira Nasyrova $^{1 \star}$, Oleg Glovatsky ${ }^{1}$, Rustam Ergashev $^{1}$, Jaloliddin Rashidov $^{1}$, and Boybek \\ Kholbutaev $^{2}$ \\ ${ }^{1}$ Tashkent Institute of Irrigation and Agricultural Mechanization Engineers, Tashkent 100000, \\ Uzbekistan \\ ${ }^{2}$ Jizzakh Polytechnical Institute, Jizzakh, Uzbekistan
}

\begin{abstract}
The aim of the research is to identify the hydrodynamic regularities in the improvement of operating modes in the water supply structures of pumping stations with vertical vane pumps. The authors studied the conditions for supplying water to the pumping station and the flow path of the pumps of the OP2...OP10 type. The curvature of the flow jets causes the swirl of the flow in front of the impellers, directed counterclockwise for the units located to the left of the axis in the direction of the flow and clockwise - located to the right. With such a flow structure, in the most unfavorable hydraulic conditions there are pumps, the direction of rotation of the impellers of which coincides with the direction of the natural swirl of the flow. The nature of hydraulic losses in the impeller of an axial pump in a wide range of feed changes within (0.1...0.4) Qo has been established. When the direction of rotation of the vortex $\alpha$ coincides with the direction of rotation of the pump, the decrease in flow reaches 0.5 $\mathrm{Q}_{0}$ for OPV 10 pumps, and $\left(0.6 \ldots\right.$ 0.7) $\mathrm{Q}_{0}$ for OP2...OP6 pumps. Impellers of axial-flow pumps must be designed taking into account shear phenomena.
\end{abstract}

Keywords: pumping stations, vane pumps, pumping units, water supply, structures, water intakes.

\section{Introduction}

The system of the Ministry of Water Management of the Republic of Uzbekistan currently operates more than 1600 pumping stations (PS), 5 thousand pumping units. Over $50 \%$ of the irrigated lands of the republic are provided with machine water lifting. By reducing the specific energy consumption, monitoring and increasing the average operating efficiency of the PS elements, operating costs can be significantly reduced. Of particular importance in modern conditions are recommendations for the reconstruction of PS to improve their performance.

The experience of the PS operation shows that for the commissioned large machine channels (Amukarakul, Amubukhara, Amuzang, Jizzakh, Karshi, Sherabad) a number of significant drawbacks are inherent, caused by the lack of scientifically substantiated

\footnotetext{
* Corresponding author: vohidov.oybek@bk.ru
} 
methods of design and operation of water supply elements [1-3]. The problem of energy saving at water lifting facilities is defined as a major national economic problem that requires urgent solutions. Saving electricity at the PS can be achieved by creating the necessary back-up modes in the supply channels. At the same time, the level of the lower pool of the PS increases and its geometric head decreases. This, in addition to saving energy, also improves the cavitation conditions of the pumps $[4,5]$.

The introduction of devices that improve the hydraulic conditions for supplying water to the pumps provides savings. So, for example, at the large Sherabad PS, the power of the extreme pumps is 6900 and $7100 \mathrm{~kW}$, and the average ones are 6200 and $6400 \mathrm{~kW}$. The difference between them is $(6900+7100) / 2-(6700+6400) / 2=700 \mathrm{~kW}$, with an average operating time of 3000 hours, the overconsumption of energy is $700 \times 3000=$ more than $2100000 \mathrm{~kW}[6,7]$.

Optimization tasks for improving the hydraulic conditions of water supply to the pumps from the front chamber were solved in $[8,9]$. The use of the principle of dissipation made it possible to extend the regularities of dividing the flow into transit and vortex from hydraulic structures to the flow path of pumps; in this case, the pump runs at reduced flow. The design of the water supply structures is designed according to traditional layouts, which do not take into account the peculiarities of the hydraulic operating conditions of the water supply complex $[10,11,12]$.

\section{Materials and methods}

For a hydraulically favorable pump mode, the authors have proposed new designs for the water intake of an open watercourse, a water intake, and suction pipes, which significantly improve the operating conditions of the main hydraulic elements coupled with the pump unit $[13,14,15]$. The use of new energy-saving operating modes provides for the improvement of the regime of the water supply structures of the PS, which gives significant savings.

When developing measures that facilitate the operating conditions and increase the stability of the operation of large PS, the following methods of analytical generalization of laboratory and field research materials were used. The traditional hydrodynamic equations were used in the theoretical substantiation of the choice of the kinematics of fluid movement in the feed to the pump path of the PS, the permissible suction height, local hydraulic resistances [16-28]. Experimental studies used a method based on the theory of hydrodynamic similarity of flows and planning a scientific experiment with mathematical modeling [28-34].

\section{Results and discussion}

The whole range of operational measures related to hydraulic, mechanical and electrical processes should provide an improvement in the energy performance of the pumps, i.e. maintain a high value of their efficiency. The experience of the PS operation has shown that many of them operate with a flow significantly lower than the design ones. The main reasons for this are the unsatisfactory hydraulic regime of the water supplying hydraulic structures.

The hypothesis of an increase in the flow rate when the directions of rotation of the vortex and the pump impeller do not coincide looks theoretically justified (Fig. 1). Fig. 1 shows the change in the conditions for water supply by pumps OP2-87 MK PS M-2-1 in the Kashkadarya region, depending on the swirl angle of the flow. 

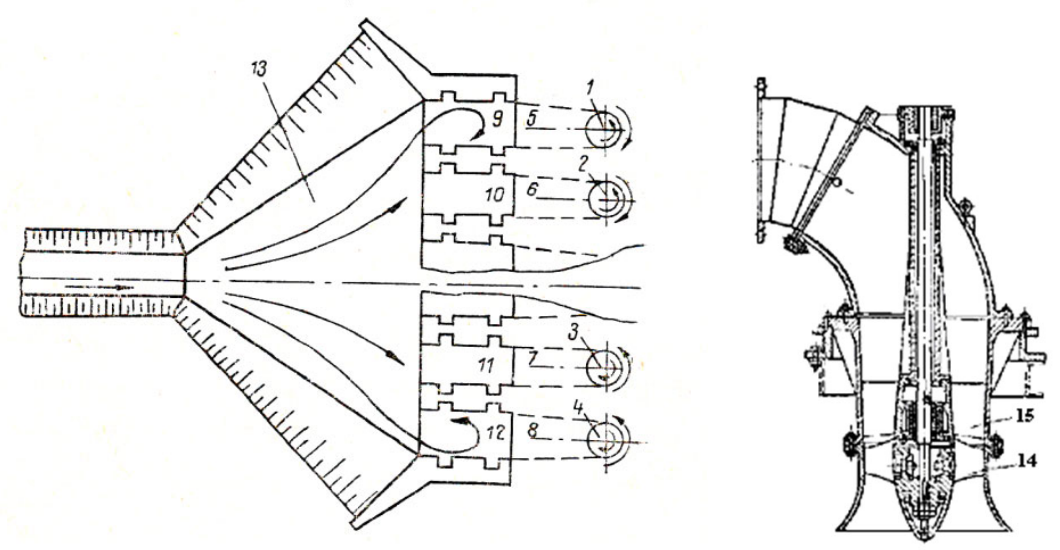

Fig 1. Plan of water supply to the pumping station and section of the flow path of the OP2 pumps.

The curvature of the flow jets causes the flow swirling in front of the impellers, directed counterclockwise for the units located to the left of the axis along the flow direction and clockwise - located to the right $[11,20]$. With such a flow structure, in the most unfavorable hydraulic conditions there are pumps, the direction of rotation of the impellers of which coincides with the direction of the natural swirl of the flow, which leads to intense vortex formation.

In the method proposed by the authors, which consists in changing the structure of the flow in front of the impellers of the units, the rotation of the impellers located to the left of the axis along the flow direction is directed clockwise, and to the right of the axis, counterclockwise.

An example of the method is illustrated in Fig. 1, which shows a plan of the pumping station. At a pumping station containing axial units $1 \ldots 4$, suction pipes $5 \ldots 8$, water intake chambers $9 . .12$ and an advance chamber 13, before starting, the connection diagram of the windings of the electric drive of the units is changed so that the rotation of the impellers of the units 1, 2 is directed clockwise, and units 3,4-counterclockwise, while using impellers with a mirror design.

As a result, the intensity of funnel formation at units 1,2 decreases, the supply of the units is leveled, and the hydraulic efficiency increases (Fig. 2).

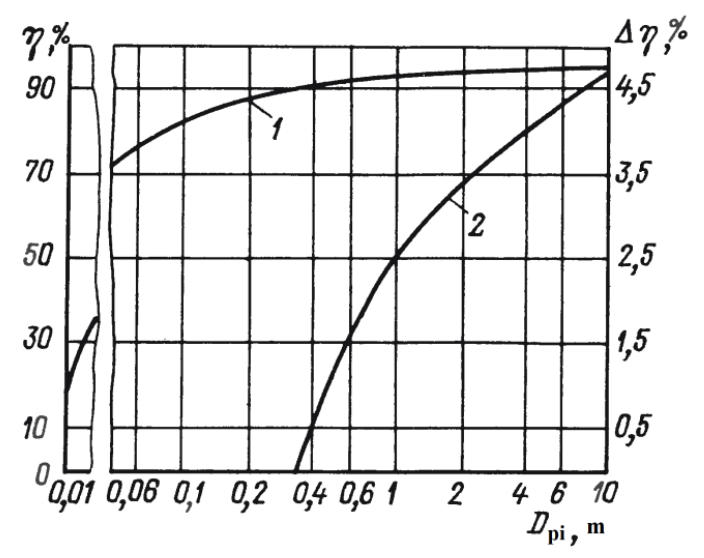

Fig 2. Change in the hydraulic efficiency of the OP2 pumps during model tests.

Change in the hydraulic efficiency of the OP2 pumps taking into account the scale effect (curve 2) during the transition from the model pump impeller $\mathrm{D}_{\mathrm{pi}}=0.3 \mathrm{~m}$ to the nature. The 
implementation of the described proposal will make it possible to dramatically expand the use of axial pumps in reclamation systems.

The fact of a decrease in flow due to vortex formation can be weakened by the introduction of methods for regulating the units by changing the direction of their rotation.

It was found that when the direction of flow deviates from the ideal at the inlet to the impeller, the pump flow varies within $(0.1 \ldots 0.4) \mathrm{Q}_{0}$. When the direction of rotation of the vortex $\alpha$ coincides with the direction of rotation of the pump, the decrease in flow for OPV 10 pumps reaches $0.5 \mathrm{Q}_{0}$, for pumps OP2...OP6 - $(0.6 \ldots 0.7) \mathrm{Q}_{0}$ (Fig. 3 ).



Fig. 3. Change in pump flow when the direction of flow deviates at the inlet to the impeller.

Reverse vortex flows are associated with the phenomena of increased non-stationarity of the flow, which cause increased noise and vibration of the pump. Low-frequency oscillations increase especially strongly [21]. As a result, in a number of cases, the zone of operating modes of a vertical pump is limited in the area of underloading by the flow rate, at which reverse flows occur from the impeller to the suction pipe.

The secondary flows arising in the space between the blades under the influence of the «relative vortex» lead to a change in the conditions of the flow on the blades. This effect is most pronounced in axial impellers.

Flow studies show that at reduced feeds, before the onset of reverse flows at the inlet of the impellers, a stall flow around the inlet edges is observed. The abrupt nature of the appearance of reverse flows and the intensity of the swirling of the flow caused by them in the flow path of the pump give reason to believe that the mechanism of the occurrence of reverse flows is associated with the development of vortex zones and their stability in the front chamber [34-39].

A system of vortices «suspended» from the trailing edges of the blades arises, rotating together with the impeller. The transition from the state of a vortex localized at the entrance edge to a vortex propagating from the water intake occurs abruptly and determines a qualitative change in the flow structure. The vortices are accompanied by water moving in the opposite direction and form a certain ring-shaped reverse flow area.

The flow pattern in the flow path 15 is determined by the following conditions: on the circle of radius $\mathrm{R}<1$ of the impeller 14 there are $p$ vortices of intensity (Fig. 1). The direction of their rotation is positive, i.e. counterclockwise, and coincides with the direction of rotation of the impeller. The outer boundary is a circle of unit radius. Outside of it, there are also $p$ vortices of equal intensity, but with reverse rotation. These vortices are located on a circle of radius $1 / R$.

We use the method for solving plane problems of the potential flow of an inviscid incompressible fluid using complex flow functions [16]. By assigning different values to this value $(\mathrm{n}=0,1,2 \ldots)$, we obtain a series of streamlines covering the system of $p$ vortices and depicting the circular motion of the fluid. Equal increments of the index $n$ 
correspond to equal flow rates between adjacent streamlines.

For $\mathrm{n}-0$, we obtain the streamline equation in the form of a circle of unit radius, which coincides with the outer boundary of the flow region. The vortex system moves at the same angular velocity as the impeller.

Taking into account the influence of secondary flows, assumptions were made based on the results of an experimental study of the flow in hydraulic structures of the PS and pumps $[11,12]:$

- the greatest additional tangential flow velocities are concentrated on the surfaces of the sleeve and the impeller chamber;

- in the transit flow, hydraulic losses are mainly determined by profile and stall losses.

For each elementary crown, the theoretical head, hydraulic losses, and the diffuser coefficient of the flow are calculated, where the usual notation from the velocity triangles at the inlet and outlet of the impeller is used [18].

By analogy with the well-known classifications of cavitation phenomena, we will divide losses into 4 types: profile (on blades, streamlined by the flow), stall (after flow), slotted (at the end of the blade) and induced from the suction pipe.

For axial-flow pumps of the OPV type, the mode of the beginning of the stall flow around the blades corresponds to the efficiency $=75 \ldots 85 \%$, when the diffuser coefficient of the flow reaches a value of $0.55 \ldots 0.6[3,9]$.

The flow at the dip boundary of the characteristics of axial pumps with a developed stall along the entire blade height is $70 \ldots 80 \%$ of the flow corresponding to the beginning of the stall flow around the root sections of the impeller blades.

The authors have expanded the possibility of using this method when creating an invention, which relates to hydraulic structures and can be used mainly in the front chambers of PS, HPP and PSP.

Devices for changing the flow structure were analyzed, including diffusers, consisting of transverse walls located in the expansion section in the front chambers, made in the form of a partition structure $[13,14]$. These devices cover part of the cross-section of structures up to $1 / 4$ of the flow depth from below or $0.1 \ldots 0.3$ from above.

However, given the great depths and dimensions of the fore-chambers of modern large stations, these devices are not able to actively influence the distribution of the vortex branches over the entire depth of the flow, which leads to an intensification of the exchange of velocity impulses and pressures between the transit and vortex layers with the opposite direction of velocities. In addition, with a large number of units at the stations, the devices cannot be designed with the ability to provide optimal hydraulic conditions for supplying water to all units with various combinations of their operation. So, during the operation of only part of the units against non-operating units, developed vortex and stagnant zones are formed, leading to siltation and distortion of the conditions for supplying water to the units.

To create a parallel-stream flow, the forechambers of large stations are made with side vertical walls in front of the station building, however, the objective need for a bottom slope in front of the suction pipes leads to an increase in the free cross-section of the forechambers, powerful whirlpools, silting up to $30-40 \%$ of the design volume, vortex zones and funnels in front of 2 water intake.

The funnels formed in the water intake chambers with periodic air suction adversely affect the pump parameters. On the basis of research by Research Institute of Irrigation and Water Problems, it was found that when up to $3 \%$ of air enters the suction pipe, the pump flow decreases by $16 \%$, and the efficiency decreases by $9 \%$. The instability of the funnels leads to additional alternating loads on the working bodies of the pumps.

With the introduction of the new invention of the authors, a decrease in the intensity of funnel formation in the water intake chambers of pumping stations, prevention of air leakage into the suction pipes of hydraulic units is achieved [22]. The task is achieved by 
the fact that the water intake chambers of the units, the axes of which are located at an angle to the axis of the water flow, are equipped with a conical regulating vortex damper with curvilinear inclined blades facing the convex side in the direction opposite to the rotation of the funnel.

The essence of the invention is illustrated by a drawing (Fig. 4), which shows a diagram of a device for regulating the supply of the PS, a plan of the PS and a regulating vortex arrester on a scale of 20: 1 are presented.
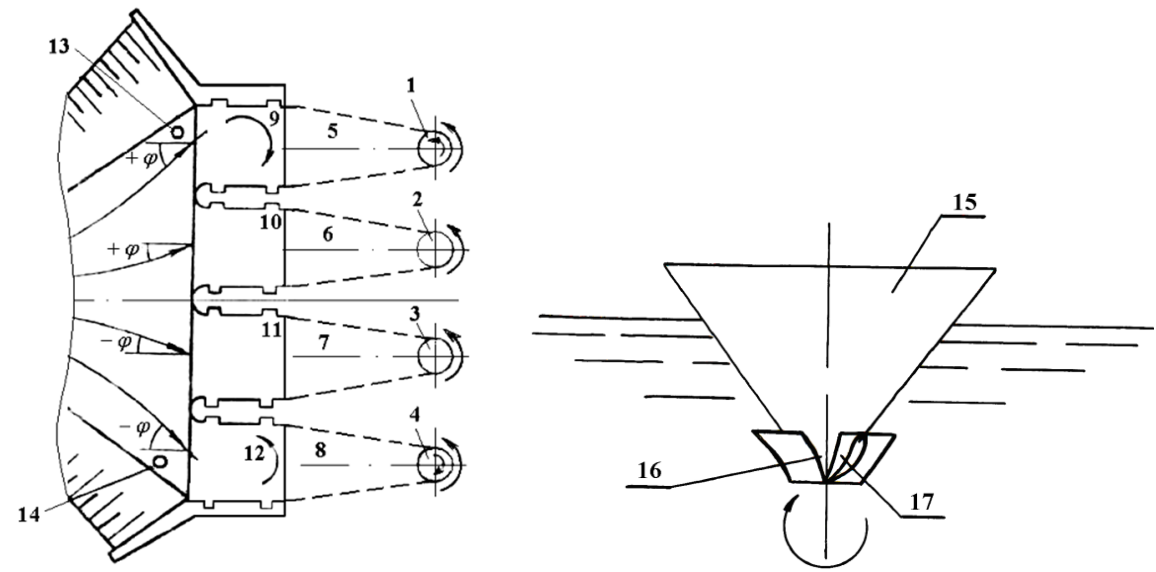

Fig 4. Device for regulating the PS supply.

The device for regulating the PS supply contains vane pumping units $1-4$, suction pipes 5-8 and water intake chambers 9-12. The water intake chambers 9 and 12, the axes of which are located at an angle to the axis of the water flow, are equipped with regulating vortex arresters 13 and 14 .

The regulating vortex damper consists of a body 15 made in the form of a cone, the top of which is directed towards the water intake opening of the suction pipes. At the top of the cone, coaxially to it, there is a light turbine wheel 16 with curved blades 17 facing the convex side towards the rotation of the funnel.

The method of operation of the device includes damping the intensity of the funnel in the suction pipes and changing the amount of swirling flow in front of the impellers of pumps 1-4.

To increase the flow, a regulating vortex damper 13 is installed in front of the unit 1 , the direction of rotation of which coincides with the direction of rotation of the flow swirl, and to reduce the flow, the regulating vortex damper 14 can be installed in front of the unit 4 with opposite rotation. If the direction of rotation of the impeller and the direction of swirling are opposite, then this leads to an increase in the pump head, if their directions of rotation coincide, then to a decrease in the head. Thus, swirling the flow in front of the pump changes its pressure characteristic. A change in the pressure characteristic of the pump with a constant characteristic of the network leads to a change in its flow.

The regulating vortex damper must be made sealed to maintain the buoyancy of the device and is placed in the water intake chamber of the hydraulic unit subject to spontaneous funnel formation. The presence of a backwater of the surface layers of the flow in front of the water intake prevents the regulating vortex damper from «drifting» beyond the limits of the water intake chamber limited on three sides by abutments.

When a spontaneous funnel occurs due to the oblique approach of the flow, the regulating vortex arrester is included in the circular motion of the surface layers of water around the funnel axis, which is characterized by a change in the peripheral velocity. Under the influence of the difference in flow velocities around the conical body 15 in the radial 
section, the regulating vortex damper moves to the center of the funnel and takes a stable position along its axis. Due to the friction of the rotating water on the side surface of the housing, a torque is generated directed towards the rotation of the funnel. The rotation of the regulating vortex damper itself is prevented by the moment from the reaction of the device, which arises when the downward vortex flows around the curved blades 17 of the wheel 16, which are convex in the direction opposite to the rotation of the funnel.

The execution of the profile of the blades curvilinear with an angle of inclination to the vertical axis of the regulating vortex damper guarantees the direction of the reaction of the wheel 16 towards the funnel.

In the conditions of spontaneous formation of unstable funnels, which include water intakes of hydraulic units, the regulating vortex arrester of the proposed design is constantly in a state of complex hydrodynamic equilibrium with the surrounding flow. The complexity of such hydrodynamic equilibrium lies in the fact that, depending on the ratio of the parameters of the body 15 and the wheel 16, as well as the changing situation (the flow rate of the hydraulic unit, the water level in the intake chamber, the combination of the operating units), the regulating vortex arrester differentially reacts to all phases of occurrence and decay of the funnels. In two stages, the control vortex damper is at rest or rotates towards the funnel if the moment from the reaction of the impeller exceeds the main torque, or rotates with the funnel, but at a lower angular velocity, when the main torque exceeds the moment from the reaction of the wheel 16. In any case the regulating vortex damper has a braking effect on the surface layers, reducing the intensity of vortex formation and eliminating the penetration of air into the suction pipe of the hydraulic unit.

The regulating vortex arrester of the proposed design is advisable to use in structures with large fluctuations in the water level, as well as in the intake chambers of those operating hydraulic units where it is structurally impossible to increase the pump head to eliminate cavitation modes or change the hydraulic conditions of the flow supply.

A significant difference of this solution from the known ones is that when the wheel interacts with the downward flow of water, a reactive torque appears in the funnel, which prevents the development of the funnel. Thus, a double effect of eliminating local vortex zones, funnels and vortex formation and regulation of the PS supply is created.

At the same time, the regulation of the multi-unit PS flow and the swirling of the flow in front of the pump changes its operating characteristic. A change in the pump characteristic with a constant characteristic of the hydraulic parameters of the water supply structures leads to a calculated change in the PS supply.

\section{Conclusions}

1. A review of works devoted to improving the operating modes of the PS with vertical vane pumps showed that the developed mathematical models describe individual processes occurring in the water supply structures of the PS and most of them are not suitable for the development of the most profitable modes of operation of the irrigation PS. The problem of unsteady water movement in the flow path of hydraulic units has not been resolved.

2. A change in the pump characteristic with a constant characteristic of the hydraulic parameters of the water supply structures leads to a calculated change in the PS supply. The authors studied the conditions for supplying water to the pumping station and the flow path of the pumps of the OP2 ... OP10 type. The curvature of the flow jets causes the swirl of the flow in front of the impellers, directed counterclockwise for the units located to the left of the axis in the direction of the flow and clockwise - located to the right. With such a flow structure, in the most unfavorable hydraulic conditions there are pumps, the direction of rotation of the impellers of which coincides with the direction of the natural swirl of the flow, which leads to intense vortex formation. 
3. Hydraulic losses in the impeller of an axial pump vary considerably over a wide range of flow rates. It was found that when the direction of flow deviates from the ideal at the inlet to the impeller, the pump flow varies within $(0.1 \ldots 0.4) \mathrm{Q}_{0}$. When the direction of rotation of the vortex $\alpha$ coincides with the direction of rotation of the pump, the decrease in flow reaches $0.5 \mathrm{Q}_{0}$ for OPV 10 pumps, and $\left(0.6 \ldots\right.$ 0.7) $\mathrm{Q}_{0}$ for OP2 $\ldots \ldots$ OP6 pumps. Impellers of axial-flow pumps must be designed taking into account shear fact.

4. The authors have expanded the possibility of using the method of supplying water to hydraulic structures and can be used mainly in the front chambers of PS, HPP and PSP when creating a device for regulating the supply of PS, which regulates vane pumping units, and water intake chambers. A double effect of eliminating local vortex zones, funnels and vortex formation and regulating the characteristics of the units is created.

\section{References}

1. B. Uralov, M. Mamazhanov, O. Glovatsky, Proceedings of the VI International Scientific and Practical Conference «Problems of Science and Education in Modern Conditions» Shymkent, 280-283 (2009)

2. O. Glovatskiy, Sh. Sharipov, Sh. Tolipov, Materials of the Republican scientific and practical conference dedicated to the improvement of the village, 126-130 (2009)

3. Sh. Rustamov, O. Glovatskiy, S. Jankabilov, S. Gadaev, Problems of energy and resource saving, 3-4, 143-148 (2017)

4. D. Bazarov, Channel process (TIIAME, 641, Tashkent, 2018)

5. Sh. Rustamov, N. Nasyrova, Materials of the international scientific-practical conference «Ways to improve the efficiency of irrigated agriculture» Novocherkassk, 3(59), 27-31 (2015)

6. Sh. Rakhimov, I. Begimov, Kh. Gafforov, Problems of computer science and energy, I, 3-4, 48-55, Tashkent (2014)

7. A. Rudnev, On the operation of flap pumps at reduced feed rates, in Proceedings of VNIIGidromash, Moscow, 30-45 (1984)

8. O. Glovatskii, On the Mathematical Description of the Flow in Ahead Chambers, Academy of Sciences of the Uzbek SSR, STN, 5, 72-76 (1984)

9. O. Glovatskiy, N. Nasirova, F. Artikbekova, The Northern Sea Route, water and land transport corridors as the basis for the development of Siberia and the Arctic in the 21st century, I, 69-74, Tyumen: TIU (2018)

10. N. Ismoilov, N. Nasirova, B. Kholbutaev, Kh. Khusanbayeva, O. Nazarov (IPICSE 2020) IOP Conf. Series: Materials Science and Engineering, 1030, 012156 (2021) DOI: $10.1088 / 1757-899 X / 1030 / 1 / 0121561$

11. O. Glovatsky, R. Ergashev, N. Nasirova, B. Kholbutaev, Kh. Khusanbayeva (IPICSE 2020) IOP Conf. Series: Materials Science and Engineering, 1030, 012115 (2021) DOI: 10.1088/1757-899X/1030/1/0121151

12. E. Kan, A. Muratov, M. Yusupov, N. Ikramov, Calculation of water hammer on the pressure pipeline of modernized irrigation pumping station, IOP Conf. Series: Materials Science and Engineering, 1030, 012127 (2021) DOI:10.1088/1757$899 \mathrm{X} / 1030 / 1 / 012127$

13. O. Glovatsky, Patent Combined floating structure of an open water intake, No. FAP 00511, 26.11.2009. No. 12 (2009)

14. V. Altunin, O. Glovatsky, G. Malaev, A. Turaev, Device for changing the structure of the flow in the water intake of multi-unit pumping stations, hydroelectric power plants and pumped storage power plants, Invention SU 1744183 A1, E 02 V 8/06 Byul. 24 (1992)

15. O. Glovatskiy, R. Ergashev, Device for supplying liquid at the inlet to the pump № 
FAP 01069. 21.01.2016.

16. A. Zuykov, Hydraulics, 1, 456 (2016)

17. N. Barishnikov, D. Isaev, Channel processes, St. Petersburg. Ed. Russian State Hydrometeorological University, 459 (2014)

18. D. Bazarov, International Academy Journal Web of Scholar, 1 (19), 26-32 (2018), URL: ws-conference.com/ (last accessed: 25.04.2021)

19. D. Bazarov, 17/2017 «Development of recommendations for the prevention of channel deformations in the downstream pools of reservoirs» Ministry of Agriculture and Water Management of the Republic of Uzbekistan, pp 80, (Tashkent 2017).

20. B. Chumachenko, Theoretical foundations and experimental studies with the aim of creating flow-through parts of vane pumps that provide a combination of high efficiency, suction capacity and low vybrat (Avtoref. All-Union Scientific Research Design and Technological Institute of Hydraulic Engineering, Moscow, 35, 2002)

21. A. Krutov, R. Choriev, B. Norkulov, D. Mavlyanova, A. Shomurodov, Mathematical modelling of bottom deformations in the kinematic wave approximation, IOP Conf. Ser. Mater. Sci. Eng., 1030, 012147 (2021).

22. A. Krutov, B. Norkulov, F. Uljaev, F. Jamalov, Results of a numerical study of currents in the vicinity of a damless water intake, IOP Conf. Ser. Mater. Sci. Eng., 1030, $012121(2021)$

23. A. Krutov, B. Norkulov, D. Mavlyanova, Simulation of spreading of non-conservative passive substances in water bodies, IOP Conf. Ser. Mater. Sci. Eng., 883(1), 012028 (2020)

24. A. Krutov, B. Norkulov, P. Nurmatov, M. Mirzaev, Applicability of zero-dimensional equations to forecast nonconservative components concentration in water bodies, IOP Conf. Ser. Mater. Sci. Eng., 883(1), 012028 (2020)

25. A. Krutov, B. Norkulov,F. Artikbekova, P. Nurmatov, Optimal location of an intake at a reservoir prone to salt diffusion, IOP Conf. Ser. Mater. Sci. Eng., 869(7), 072020, (2020)

26. B. Shokirov, B. Norkulov, Kh. Nishanbaev, M. Khurazbaev, B. Nazarov, Computer simulation of channel processes, E3S Web of Conferences, 97, 05012, (2019)

27. M.bShomayramov, B. Norkulov, J. Rakhmanov, D. Tadjiyeva, J. Suyunov, Experimental researches of hydraulic vacuum breakdown devices of siphon outlets of pumping stations, E3S Web of Conferences, 97, 05009, (2019)

28. O. Glovatsky, O. Azizov, F. Bekchanov, A Gazaryan, M. Shomayramov, N. Ismailov, CONMEDCHYDRO-2020, IOP Conf. Series: Materials Science and Engineerig, 883(1) 012032 (2020)

29. B. Obidov, O. Vokhidov, D. Tadjieva, U. Kurbanova, A. Isakov, Hydrodynamic effects on the flow elements of the downstream devices in the presence of cavitation, IOP Conf. Ser. Mater. Sci. Eng., 1030, 012114 (2021).

30. D. Bazarov, B. Norkulov, O. Vokhidov, F. Uljaev, Z. Ishankulov, Two-dimensional flow movement in the area of protective regulatory structures, IOP Conf. Ser. Mater. Sci. Eng., 890, 012162 (2020)

31. O. Glovatskiy, N.Nasyrova The device for regulating the flow of the pumping station № IAP 06269. Invention. (2020)

32. D. Bazarov, N. Vatin,B. Obidov, O. Vokhidov, Hydrodynamic effects of the flow on the slab of the stand in the presence of cavitation, IOP Conf. Ser. Mater. Sci. Eng., 1030, 012110 (2021).

33. D. Bazarov, I. Markova, B. Norkulov, O. Vokhidov, Hydraulic aspects of the layout of head structures during water intake from lowland rivers, IOP Conf. Ser. Mater. Sci. Eng., 1015, 012041 (2021)

34. D. Bazarov, I. Markova, S. Sultanov, F. Kattakulov, Dynamics of the hydraulic and 
alluvial regime of the lower reaches of the Amudarya after the commissioning of the Takhiatash and Tuyamuyun hydrosystems, IOP Conf. Ser. Mater. Sci. Eng., 1030, 012110 (2021)

35. D. Bazarov, O. Vokhidov, Extinguishing Excess Flow Energy in Spillway Structures, Proceedings of EECE 2020, LNCE, 150, 535-545 (2021) DOI: 10.1007/978-3-03072404-7 52

36. B. Matyakubov, I. Begmatov, I. Raimova, G. Teplova, Factors for the efficient use of water distribution facilities, IOP Conf. Ser. Mater. Sci. Eng., 883, 012025 (2020)

37. B. Uralov, N. Rakhmatov, S. Khidirov, F. Uljaev, I. Raimova, Hydraulic modes of damless water intake, IOP Conf. Ser. Mater. Sci. Eng., 1030(1), 012123 (2021)

38. D. Bazarov, I. Markova, I. Raimova, Sh. Sultanov, Water flow motion in the vehicle of main channels, IOP Conf. Ser. Mater. Sci. Eng., 883, 012025 (2020)

39. D. Bazarov, I. Markova, B. Norkulov, K. Isabaev, M. Sapaeva, Operational efficiency of water damless intake, IOP Conf. Ser. Mater. Sci. Eng., 869(7), 072051 (2020) 